Apidologie, 1970, 1 (2), 115-142.

\title{
ÜBER DIE FÄHIGKEIT DER BIENENKÖNIGIN (APIS MELLIFICA L.) ZWISCHEN ARBEITERINNEN- UND DROHNENZELLEN ZU UNTERSCHEIDEN
}

\author{
Sur l'aptitude de la reine \\ à distinguer les cellules d'ouvrières des cellules de mâles
}

Nikolaus KOENIGER

Institut für Bienenkunde der Universität, Frankfurt am Main, Oberursel

SUMMARY

ON THE NATURAL DISPOSITION OF THE QUEEN

FOR DISTINGUISHING WORKER BEE CELLS FROM MALE CELLS

The observation of the queen honeybee during oviposition showed that, during her inspection of a cell, both front legs are introduced into the cell. By fixing tiny " flags " (Fähnchen) at the queen's fore legs the inspection could be blocked up. After inhibited inspection the queen preponderatingly $(89 \%)$ is laying fertilized eggs into drone cells. After amputation of both trochanters the results were similar to those of blocking by " flags " (78\% worker pupae in drone cells). After an amputation of both fore legs within the femur, there were $18 \%$ worker pupae in drone cells, whereas there were only $3 \%$ after an amputation within the tibia. Obviously, the one side amputation of a fore leg does not impair much the perception $(0,3 \%$ worker pupae in drone cells). From these results it was concluded that, caused by the specific stimulus of the drone cell, the fertilization of the egg is inhibited. So, the difference between drone cells and queen cells would cause the deposition of fertilized eggs into queen cells.

\section{ZUSAMMENFASSUNG}

1. Bei eingehender Beobachtung des Eilegeverhaltens wurde gefunden, daß die Königin be der Zellinspektion beide Vorderbeine in die Wabenzelle einführt.

2. Eine reversible Blockierung der Inspektion wurde durch Anbringen von "Fähnchen " an den Vorderbeinen der Königin erreicht. 
3. Nach Blockierung der Inspektion werden von der Königin in Drohnenzellen überwiegend $(89 \%)$ befruchtete Eier abgelegt.

4. Nach Amputation beider Trochanter wurden ähnliche Ergebnisse wie bei der Behinderung durch " Fähnchen " erhałten (78\% Arbeiterinnenpuppen in Drohnenzellen).

5. Die beidseitige Amputation der Vorderbeine innerhalb der Femora ergab $18 \%$ und der Tibien $3 \%$ Arbeiterinnenpuppen in Drohnenzellen.

6. Die einseitige Amputation eines Vorderbeines scheint das Erkennen nur geringfügig zu beeinträchtigen (0,3\% Arbeiterinnenpuppen in Drohnenzellen).

7. Die Ergebnisse wurden dahingehend interpretiert, daß auf Grund des spezifischen Reizmusters der Drohnenzelle die Befruchtung des Bieneneis verhindert wird. Der große Unterschied zwischen Drohnen- und Weiselzellen würde dann die Ablage von befruchteten Eiern in letztere bewirken.

\section{EINLEITUNG}

Die Kenntnisse über Verhalten und Sinnesleistugen der Arbeitsbiene wurden durch viele Untersuchungen auch während der letzten Jahre immer weiter ausgebaut, so daß die Honigbiene sicher zu den am besten bearbeiteten Objekten der Biologie gezählt werden kann. Über die Bienenkönigin dagegen liegen nur wenige Arbeiten vor. So ist die hier aufgegriffene Frage, wie die Königin zwischen Arbeiterinnen- und Drohnenzellen unterscheiden kann, seit über hundert Jahren immer wieder diskutiert worden. Das weitgehende Fehlen von experimentellen Untersuchungen kann daher nur durch die Schwierigkeiten erklärt werden, die mit der Beschaffung von so vielen Bienenvölkern und Königinnen verbunden sind, wie zu entsprechenden Experimenten benötigt werden. So wurde die hier vorliegende Arbeit erst durch den großen Bienenbestand des Institutes für Bienenkunde in Oberursel ermöglicht 123 .

\section{I. - PROBLemstellung}

In einem Bienenvolk gibt es drei verschiedene Typen von Wabenzellen. Die Arbeiterinnenzellen haben einen diagonalen Durchmesser von etwa $5,7 \mathrm{~mm}$ (eigene Messung). Ihre Tiefe beträgt 10-12 mm (eigene Messung) und die Wanddicke 0,07 mm (Martin und Lindauer, 1966). Die Arbeiterinnenzellen bilden den Hauptanteil der Waben. Daneben werden normalerweise auch zahlreiche Drohnenzellen gefunden, die in der Form mit den Arbeiterinnenzellen übereinstimmen, sich aber aufgrund der größeren Dimensionen (diagonaler Durchmesser 7,1 mm, Tiefe $15 \mathrm{~mm}$ (eigene Messung) und Wanddicke 0,09 mm (Martin

1. Herr Professor Dr. F. Rutrner gab nir die Anregung zu dieser Arbeit. Dafür sowie für die zahlreichen Diskussionen während des Fortganges der Versuche möchte ich recht herzlich danken.

2. Diese Arbeit wurde aus Mitteln gefördert, die Herrn Prof. F. Rutwnen von der deutschen Forschungsgemeinschaft zur Verfügung gestellt worden waren.

3. Frau Ing. agric. G. Alpern und Herrn Ing. agric. R. BAR-Cohen von der Experimental Beekeeping Station of the Ministry of Agriculture of the State of Israel danke ich für ihre Gastfreundschaft und Unterstützung während meines Aufenthaltes in Israel. 
Im Gegensatz zu den Arbeiterinnen- und Drohnenzellen, deren Längsachse um etwa $4^{\circ}$ nach oben von der Horizontalen abweicht, ist die Längsachse der Weiselzelle mehr oder weniger vertikal. Die Weiselzelle hat eine eichelförmige Gestalt. Der Durchmesser des runden Querschnittes beträgt an der weitesten Stelle $9 \mathrm{~mm}$ (Freudenstern, 1938). Während die anderen Zellen wiederholt zur Aufzucht von Maden und zur Speicherung von Honig und Pollen dienen, Nird die Weiselzelle nur einmal benutzt und nach dem Schlüpfen der jungen Königin von den Arbeiterinnen abgebaut.

Die Befruchtung des Eies findet während oder kurz nach der Eiablage statt (v. Siebold, 1856). Dabei wird das Ei im medianen Ovidukt an der Einmündung des Spermathekalganges vorbeibewegt und mit Sperma versehen. Dicht unterhalb der Spermatheka umschließt ein Organ, das aus mehreren Muskelgruppen aufgebaut ist, den Spermathekalgang (Spermapumpe, Bresslau, 1905). Oberhalb der Spermapumpe mündet die zweiästige Spermathekaldrüse in den Spermathekalgang ein. Die Spermapumpe und die Spermathekaldrüse werden von einem Ast des neunten Nerven des letzten (vierten) Abdominalganglions versorgt (RuTtner, 1961).

Über den Mechanismus der Spermazugabe zum austretenden Ei sind mehrere Hypothesen aufgestellt worden. Nach Bresslau 1905 und Adam 1912 soll die Spermapumpe die Zugabe des Spermas hemmen oder ermöglichen, wobei durch Kontraktionen und Erschlaffung bestimmter Muskelgruppen der Spermapumpe der Spermathekalgang geöffnet bzw. geschlossen werden soll.

Flanders (1950) betrachtet die Spermapumpe lediglich als Ventil, das sich öffnet, sobald ein $\mathrm{Ei}$ an der Mündung des Spermathekalganges vorbeigleitet. Die Aktivierung des Spermas durch das Sekret der Spermathekaldrüse soll die Zugabe des Spermas zum austretenden Ei bewirken. Soll ein Ei unbefruchtet bleiben, so unterbleibt die Sekretausschüttung der Spermathekaldruise und das unaktivierte Sperma vermag nicht den Weg bis zum Ei zurückzulegen.

Es besteht also keine Klarheit über den Mechanismus der Spermafreisetzung aus der Spermatheka. Noch weniger ist das der Fall hinsichtlich der Art seiner Auslösung.

Eine intakte, vollgepaarte Königin ist in der Lage, jede einzelne der zeitweise sechzigtausend und mehr Brutzellen eines Bienenvolkes ohne Fehler mit dem adäquaten $\mathrm{Ei}$ zu belegen, d.h. Drohnenzellen mit unbefruchteten und Arbeiterinnenzellen mit befruchteten Eiern.

Seit der Entdeckung der Parthenogenese durch Dzierzon 1845 wird die Frage diskutiert, auf welche Weise die Königin zu dieser Leistung befähigt wird.

Von den vielen Hypothesen und Spekulationen über diese Frage sollen hier nur solche besprochen werden, die zumindest keine wesentlichen Fehler in ihren anatomischen und biologischen Praemissen enthalten. So erscheint es beispielsweise wenig sinnvoll, auf eine Hypothese einzugehen, die davon ausgeht, daß der Spermathekalgang in den linken Ovidukt einmündet (BENussi-Bossi, 1901) und nicht in den medianen Ovidukt, wie schon von v. Siebold (1856) und vielen anderen Autoren beschrieben wurde. 
1. Dzierzon selbst vertrat die Ansicht, daß die Königin willkürlich die Spermazugabe zum Ei regeln könne : " Die Königin hat die Möglichkeit, nach Belieben männliche oder weibliche Eier zu legen " (Neue verbesserte Bienenzucht S. 102). Ähnliche Auffassungen wurden von v. SiEBOLd (1856), von v. BERLEPSCH (1860), NaChTSheim 1914 und Zander (1936) vertreten. Dabei ist nicht klar, was wissenschaftlich in diesem Zusammenhang unter "Belieben " oder "Willen " zu verstehen ist.

2. Eine ganz andere Hypothese, die als sogenannte Drucktheorie bis heute von vielen Bienenzüchtern vertreten wird, findet sich bei РетRunkewitsch (1901) : "Nun sind aber die Arbeiterinnenzellen viel enger als die Drohnenzellen und das erschwert das Hineindringen des Hinterleibs der Königin, kann also bei derselben einen anderen Reflex auslösen. Je nach dem Eindruck wird also die Königin reflektiv die Wirkung des den Ausführungsgang des Receptakulum schließenden Sphinkters aufheben oder denselben in tonischer Kontraktion belassen ». Geger diese Hypothese, die wohl schon vor Petrunkewitsch von einigen Imkern vertreten wurde, waren bereits verschiedene Einwände erhoben worden; so weist v. Berlepsch darauf hin, daß die Weiselzellen, die von der Königin mit befruchteten Eiern belegt werden, einen größeren Durchmesser haben als Arbeiterinnenzellen. Auch belegen nach v. BerLEPSCH Königinnen, die mit Arbeiterinnen auf Drohnenbau gesperrt werden, die Drohnenzellen mit befruchteten Eiern. V. Buttel-Reepen (1915) betont, daß das Ablegen von unbefruchteten Eiern an bestimmte biologische Perioden gebunden ist. Später wurde die "Drucktheorie» in veränderter Form von Freudenstein (1932) vertreten. Durch Messungen an frisch belegten Weiselzellen zeigte er, daß diese Zellen durch Anlage eines " Befruchtungsringes " an ihrer Öffnung auf etwa $5,37 \mathrm{~mm}$ eingeengt werden, sodaß die Öffnungsweite etwa einer Arbeiterinnenzelle entspricht. Freudenstein faßt dann seine Hypothese wie folgt zusammen : "Wohl können in der sommerlichen Brunftstimmung des ganzen Bienenvolkes die verschieden weiten Zellöffnungen - einschließlich des Befruchtungsringes am Weiselnäpfchen - Befruchtung oder Nichtbefruchtung des Eies regulieren : in den weiten Dohnenzellen ließe dann eine starke Spreizung der Hinterleibsöffnung bei der eicrlegenden Königin das Ei unbefruchtet am Samenausführungsgang vorbeigleiten; im Herbst und Frühjahr zeigt aber der Eierlegetrieb der Königin, wie alle Brunfttriebe der Arbeiterinnen, eine geringere Intensität : eine schwächere Spreizung der Hinterleibsöffnung würde infolgedessen bei der Eiablage in Drohnenzellen ebenso zur Benetzung der austretenden Eier mit Spermien führen wie in der Arbeiterinnen- und Weiselzelle " (Wesen der Bienen S. 62).

Gegen diese Hypothese muß eingewendet werden, daß durch Spreizung der Hinterleibsspalte der Königin die Einmündungsstelle des Ductus spermaticus eher verengt als erweitert wird. Es erscheint überhaupt aufgrund der Anatomie unmöglich, daß ein $\mathrm{Ei}$ austritt, ohne die Mündung des Ductus spermaticus zu berühren, da gerade an dieser Stelle ein muskulöser Zapfen, die Valvula vaginalis, in das Lumen das medianen Oviduktes hineinragt (ADAM, 1912).

3. Gontarski (1935) kommt aufgrund seiner Untersuchungen über die Maße der Wabenzellen zu einer anderen Vorstellung : " Nicht der Reiz der absoluten Größe der Drohnenzelle bedingt die Ablage von unbefruchteten Eiern, 
sondern ein bestimmtes Verhältnis zweier Wabenzellgrößen. Es erscheint die Annahme berechtigt, daß das Aussetzen der Spermapumpe bei der Drohneneiablage als Reaktion auf einen kinästhetischen Reizunterschied bei Arbeiterund Drohnenzelle anzusehen ist "GOETzE (1940) hält auch eine kinästhetische Auslösung der Spermazugabe durch verschiedene Wabenmuster für wahrscheinlich. Im übrigen betont er jedoch das Zeitgesetz des Brutinstinktes und nimnt einen periodisch verschiedenen Zustand der Samenpumpe an.

Gegen diese Hypothese muß die große Veränderlichkeit des Wabenmusters angeführt werden. Durch das Verdeckeln von Brutzellen, die sich verpuppende Larven enthalten, entsteht eine mehr oder weniger ebene Wabenoberfläche. Da jedoch häufig nicht alle beieinander liegenden Zellen zur gleichen Zeit belegt werden, sind in diese Flächen mit gedeckelter Brut oft ungedeckelte Zellen mit Eiern oder jungen Maden eingeschoben. Auf diese Weise ändert sich das Wabenmuster dauernd, und es erscheint daher fraglich, ob ein so veränderlicher Parameter zur Regulierung der Befruchtung herangezogen werden kann.

4. Freudenstein (1938) hat die Ansicht diskutiert, daß die Arbeiterinnen beim Zellputzen die Arbeiterinnen- und Drohnenzelle mit verschiedenem Speichel zur Eiablage vorbereiten. Die Königin würde dann aufgrund verschiedener olfaktorischer Reize Arbeiterinnen-und Drohnenzellen unterscheiden können. FyG (1941) findet diese Ansicht " durchaus nicht abwegig " und verweist auf das von v. Frisch (1921) untersuchte " plastische Riechen der Insekten ".

Solange keine Untersuchungen vorliegen, die qualitative oder zumindest deutliche quantitative Unterschiede in der Einspeichelung zwischen Arbeiterinnenund Drohnenzellen nachweisen, gibt es jedoch keine Anhaltspunkte, die für die Richtigkeit dieser Ansicht sprechen. Derselbe Einwand der fehlenden experimentellen Grundlage gilt auch für alle anderen aufgeführten Hypothesen. Denn trotz der recht intensiven Diskussion der Frage des Unterscheidungsvermögens der Königin zwischen Arbeiterinnen- und Drohnenzellen sind bisher nur sehr wenige Experimente unternommen worden :

1. v. Berlepsch (1860) setzte sich mit der "Drucktheorie " auseinander. Er konnte zeigen, daß eine Königin, die mit Arbeiterinnen auf reinen Drohnenbau gebracht wurde, die Drohnenzellen mit befruchteten Eiern belegte.

Aus diesem Ergebnis geht klar hervor, daß eine Königin nicht unter allen Umständen in eine Drohnenzelle ein unbefruchtetes Ei ablegt, sondern daß, wie man heute aufgrund von Erkenntnissen der Verhaltensforschung (Tinbergen, 1950 u.a.) vermuten kann, neben dem Reizmuster der Drohnenzelle noch physiologische Voraussetzungen erfüllt sein müssen, um die Spermazugabe zum austretenden $\mathrm{Ei}$ zu blockieren.

Ein ähnliches Experiment wurde von Freudenstein (1935) ausgeführt, der ein ganzes Bienenvolk auf Waben setzte, die nur aus Drohnenzellen bestanden. Bei der Ausmessung der Drohnenzellen, die mit Arbeiterinnenpuppen besetzt waren, ergab sich, daß die Königin bevorzugt in die kleinsten Drohnenzellen befruchtete Eier gelegt hatte. Die Königin scheint also in der Lage zu sein, die Zellgröße zu perzipieren. Allerdings darf in diesem Zusammenhang nicht außer Acht gelassen werden, daß die Arbeiterinnen durch das Zellputzen beeinflussen, 
in welche Zelle ein Ei gelegt wird; denn die Königin bestiftet normalerweise nur geputzte Zellen (v. Buttel-Reepen, 1915 u.a.).

2. Fyg (1943) untersuchte den Eilegeakt der Bienenkönigin. Er wiederholte einen Versuch von Huber (1814), der einer Königin beide Antennen amputiert hatte. Eine Königin ist ohne Antennen nicht mehr in der Lage, Kontakt mit den Arbeiterinnen zu halten, und geht nach ein bis zwei Tagen zu Grunde. Eine Eiablage konnte nach Amputation der Antennen nicht mehr beobachtet werden. Dagegen scheint die Königin bei Amputation nur einer Antenne bei der Eiablage nicht behindert zu sein. Aus diesen Experimenten schließt Fyg, daß die Reize, die die Eiablage auslösen, von der Königin mit Hilfe der Antennen auf enommer werden.

Hiergegen muß eingewendet werden, daß die Amputation beider Antennen als ein sehr gravierender Eingriff angesehen werden muB, und es erscheint daher möglich, daß die so herbeigeführte Verhinderung der Eiablage eher eine Folge des gestörten Allgemeinzustandes der Königin ist als eine direkte Auswirkung der Amputation auf die Perzeption vor der Eiablage.

3. Im weiteren Verlauf seiner Untersuchungen greift FYG das Problem der Reizleitung bei der Eiablage auf. Er konnte zeigen, daß die Eiablage durch die Durchtrennung des Bauchmarkes vor dem vierten Abdominalganglion blockiert wird. Eine so behandelte Königin zeigt nach FYG einen im wesentlichen intakten Ablauf des Eilegeverhaltens, lediglich das Austreten des Eies unterbleibt.

Die Eiablage kann also nicht als ein peripherer Reflex aufgefaßt werden, sondern ist nach diesen Befunden ein zentralnervös gesteuerter Vorgang.

Nach diesem Überblick über die Hypothesen und die wenigen Experimente erscheint es zunächst nötig, unbeeinflußt von den bisher geäußerten Vermutungen durch genaue Beobachtung des Eilegeverhaltens der Königin einen Ansatz für eigene Versuche zu finden. Ziel der Untersuchung soll sein, einen experimentellen Beitrag über das Unterscheidungsvermögen der Königin zwischen Arbeiterinnenund Drohnenzellen zu łeisten.

\section{II. - MATERIAL UND METHODE}

Beobachtungen und Versuche wurden im Sommer 1966, 1967 und 1968 am Institut für Bienenkunde in Oberursel durchgeführt. Dabei wurde vorwiegend mit Bienen der Rasse Apis mellifica carnica gearbeitet. Von Januar bis Mai 1967 wurde in Sarafand (Israel) mit Apis mellifica ligustica experimentiert. Zu den Versuchen wurden starke Bienenvölker mit mindestens 5 Rrutwaben verwendet. In Israel befanden sich die Völker auf Langstrothwaben in Magazinbeuten, während in Oberursel hauptsächlich Blätterstöcke mit zwölf Waben (Deutsch-Normalmaß) benutzt wurden. Alle Völker enthielten zumindest eine Wabe mit Drohnenbau.

Zur Beobachtung des Eilegeverhaltens der Königin wurde ein Beobachtungskasten mit einem Thermostaten nach Lindauer mit einem Bienenvolk (drei Brutwaben) besiedelt. Die Temperatur wurde auf $32^{\circ} \mathrm{C}$ einreguliert, was sich für die Beobachtung als sehr günstig erwies. Bei niedrigeren Temperaturen bildeten die Bienen nämlich eine dicke Schicht anf der Brutfläche und versperrten so die Sicht auf die Königin.

Das Einweiseln der Königinnen in die Versuchsvölker wurde mit Hilfe von Drahtkäfigen, die in eine Wabe eingeschnitten wurden, durchgeführt. Nach zwei Tagen wurde die gekäfigte Königin durch Ausfressen eines Zuckerteigverschlusses im Volk freigelassen. Nach dreißig Tagen, wenn 
schon die erste Brut der zugesetzten Königin ausgelaufen war, wurde mit dem Versuch begonnen. Die ersten von der Königin beeglten Drohnenzellen wurden durch ein Absperrgitter (ein Gitter, dessen Stäbe einen so großen Abstand haben, daß die Arbeiterinnen hindurchschlüpfen können, während die größere Königin es nicht passieren kann) abgetrennt. Soltte an der Königin ein Eingriff vorgenommen werden, so wurde sie aus dem Volk herausgefangen. Die Zeit außerhalb des Volkes darf nicht mehr als zehn Minuten betragen, da sonst das Wiederzusetzen ohne Käfig, bei dem die Königin mit Zuckerteig bestrichen wird, mit zu großen Verlusten verbunden ist.

Die Waben mit den Drohnenzellen wurden jeweils 15-18 Tage nach dem Auffinden der ersten Eier aus dem Volk herausgenommen. Die mittlerweile verdeckelten Zellen wurden geöffnet und das Geschlecht der verpuppten Bienen festgestellt. Die Puppen wurden einzeln aus den Zellen herauspräpariert und drei bis sechs Millimeter über dem Zellgrund der diagonale Zetldurchmesser mit Hilfe einer Schublehre (Genauigkeit 0,02 mm) gemessen. Da das Bienenwachs bei Zimmertemperatur verformbar ist, was die Präparation und ein genaues Messen sehr erschwert, wurden die Waben vorher auf etwa $-10^{\circ} \mathrm{C}$ gekühlt. Zellen mit mindestens $6,5 \mathrm{~mm}$ im Durchmesser wurden bei den Versuchen als Drohnenzellen berücksichtigt (GONTARSKı 1935 u.a.).

Im Sommer 1968 wurden Drohnenwaben bei den Experimenten benutzt, die frisch aus vorgeprägten Mittelwänden (Fa. Dadant, Hamilton Ill. U.S.A.) gebaut waren. Bei diesen Waben haben alle Zellen einen Durchmesser von etwa $7,4 \mathrm{~mm}$, sodaß auf das Ausmessen der einzelnen Zellen verzichtet werden konnte.

Im Frühjahr und Sommer wurden die Drohnenzellen von der Königin sofort bestiftet, ab August wurde es trotz intensiver Fütterung der Versuchsvölker immer schwieriger, bestiftete Drohnenzellen zu erhalten. Deshalb wurden bei sechs Versuchen die Königinnen auf Waben gesperrt, die hauptsächlich aus Drohnenzellen aufgebaut waren. In diesen Fällen wurden jedoch nur Ergebnisse berücksichtigt, bei denen die Königin vor dem Eingriff unter den gleichen Bedingungen wie im Experiment, also auf eine Wabe mit Drohnen- und Arbeiterinnenzellen gesperrt, in die Drohnenzellen nur unbefruchtete Eier gelegt hatte.

Königinnen wurden nach einem Versuch weiter verwendet, sofern sie entweder fast reine Drohnenbrut erzeugt hatten oder wenn sie nach Aufhebung einer experimentellen Behinderung eine Drohnenwabe richtig belegt hatten.

Ein Versuch dauert auf diese Weise etwa 50 Tage. Mit 28 starken Bienenvölkern und 54 Königinnen habe ich die Untersuchungen durchgeführt.

\section{II. - DAS LEGEVERHALTEN DER KöNIGIN}

Vor der Aufnahme eines Eies werden die Zellen von den Arbeiterinnen intensiv beleckt und etwa vorhandene Rückstände werden entfernt. Nicht geputzte Zellen übergeht die Königin bei der Eiablage (Buttel-ReEpen 1915).

Trifft die Königin bei ihren Eilegegängen auf eine geeignete Zelle, so bleibt sie vor der Zellöffnung stehen und senkt den Kopf, sodaß die Stirnseite parallel zur Wabenoberfläche gestellt wird. Dabei werden die Tibien des ersten Beinpaares seitlich an den Kopf angelegt. In dieser Stellung werden nun der Kopf und das erste Beinpaar vollständig in die Zelle hineingesteckt, bis das Thoraxschild dorsal an den Zellrand stößt. So verharrt die Königin kurze Zeit, während sie die Tibien des mittleren Beinpaares von außen an die Zelle anlegt. Anschließend werden Kopf und erstes Beinpaar aus der Zelle herausgezogen (Abb. 2-4).

Das eben beschriebene Verhalten wird als Inspektion der Zelle bezeichnet. Die Dauer der Inspektion vom Einführen des Kopfes in die Zelle bis zum Herausziehen beträgt etwa drei Sekunden (min. 1,5 sec., max. 10 sec.) Auf die Inspektion folgt entweder die Eiablage, oder die Königin entfernt sich und sucht eine neue Zelle auf. Unter den nicht sehr natürlichen Bedingungen im Beobachtungskasten (alle Waben sind in einer Ebene angeordnet und nicht parallel nebeneinander wie im natürlichen Bienenvolk) wurde durchschnittlich nach zwei 

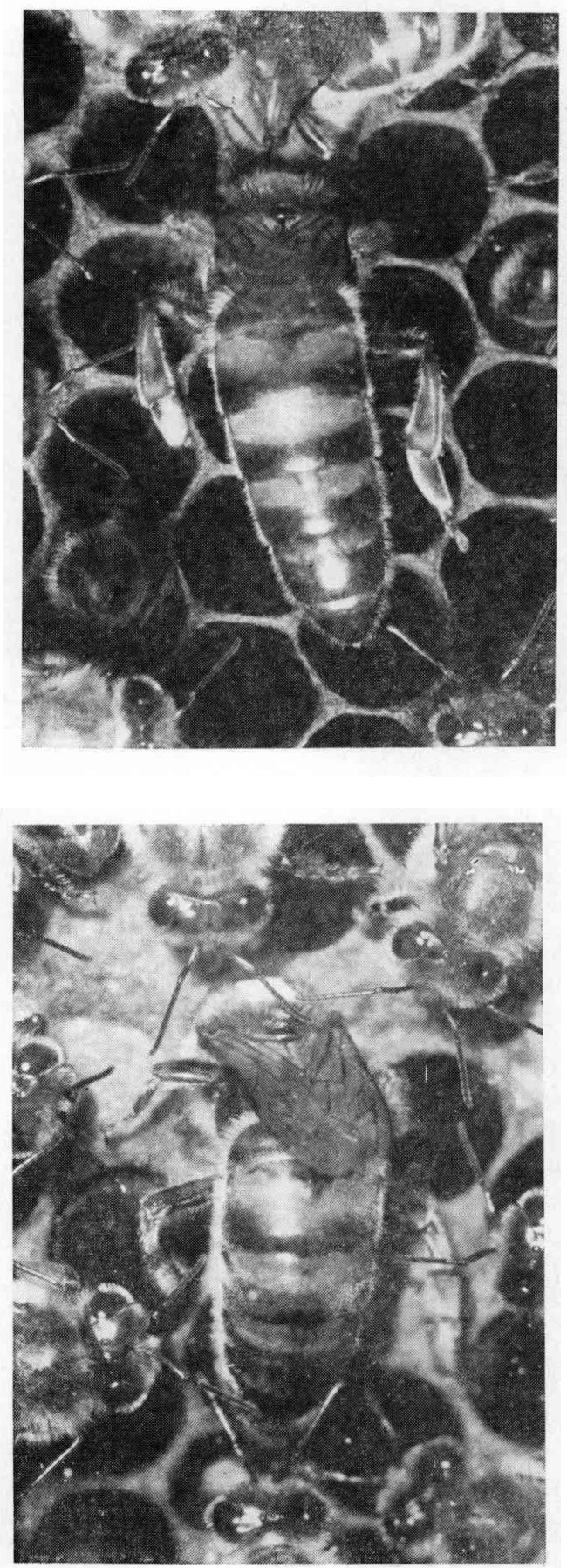

Aвв. 2. - Inspektion

Nachdem der Kopf mit dem ersten Beinpaar in die Zelle eingeführt ist, bis das Rückenschild an den Zellrand stößt, wird das mittlere Beinpaar von außen an die inspizierte Zelle angelegt.

\section{FIG. 2. - Inspection de la reine}

Lorsque la tête a été introduite dans la cellule avec la première paire de pattes jusqu'à ce que le bouclier dorsal touche le bord de la cellule, la paire de pattes médianes est placée sur la cellule inspectée.

ABB. 3. - Inspektion

Das Anlegen des mittleren Beinpaares an die inspizierte Zelle ist nicht möglich, wenn diese von verdeckelten Zellen umgeben ist.

\section{FIG. 3. - Inspection}

Il est impossible de placer la paire de pattes médianes sur la cellule inspectée si celle-ci est entourée de couvain operculé. 


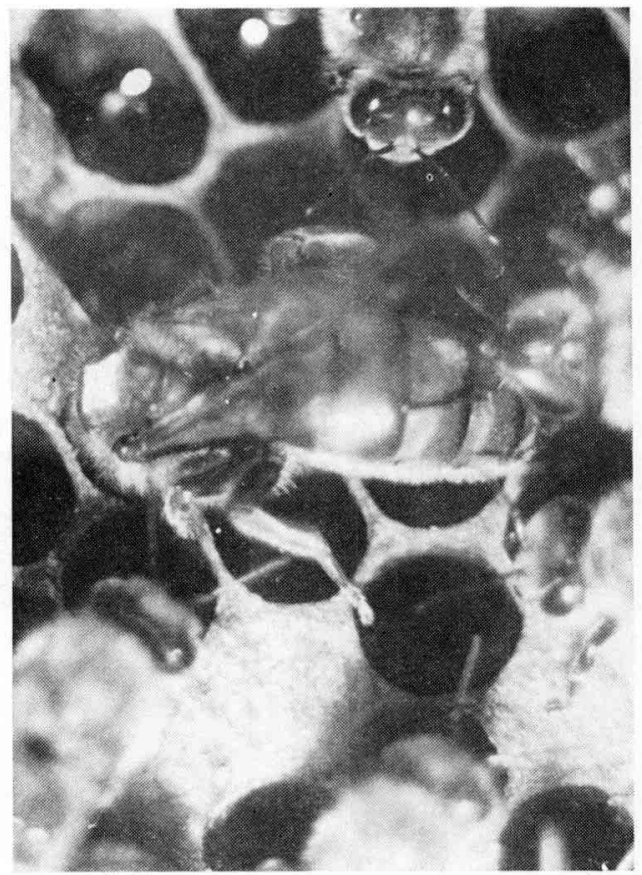

Aвв. 4. - Ende der Inspektion

Der Kopf und das erste Beinpaar werden aus der Zelle herausgenommen.

Fig. 4. -- Fin de l'inspection

La reine retire la tête et la première paire de pattes de la collule.

Inspektionen eine Eiablage beobachtet. Eierlegen ohne vorhergegangene Inspektion konnte nicht bemerkt werden.

Wird ein Ei abgelegt, so werden nach der Inspektion die Gelenke zwischen Tibia und Femur des mittleren und hinteren Beinpaares gestreckt, sodaß sich der Körper der Königin von der Wabenoberfläche abhebt. Dabei bewegt sich die Königin einige Schritte vorwärts und krümmt das Ende des Abdomens nach vorn, bis es sich über der Öffnung der vorher inspizierten Zelle befindet. Beim folgenden Einführen des Hinterleibes in die Zelle ist bei einigen Königinnen eine Drehung des Körpers um die Längsachse der Zelle zu beobachten, sodaß der Kopf der Königin bei der Eiablage dann nach unten zeigt. Der Eilegevorgang vom Einführen des Abdomens in die Zelle bis zum Herausnehmen dauert etwa 25 sec. (min. 16 sec., max. 42 sec.) (Abb. 5, 6).

Im allgemeinen laufen Inspektion und Eilegeakt so wie oben beschrieben ab, doch wurden auch kleinere Abweichungen beobachtet. So ist z. B. das Anlegen des mittleren Beinpaares von außen an die inspizierte Zelle nicht möglich, wenn diese von verdeckelten Brutzellen umgeben ist. Auch werden die einzelnen Bewegungen der Königin oft von vorbeilaufenden Arbeiterinnen gestört, ohne daß es zu einer Verhinderung der jeweiligen Eiablage käme. 


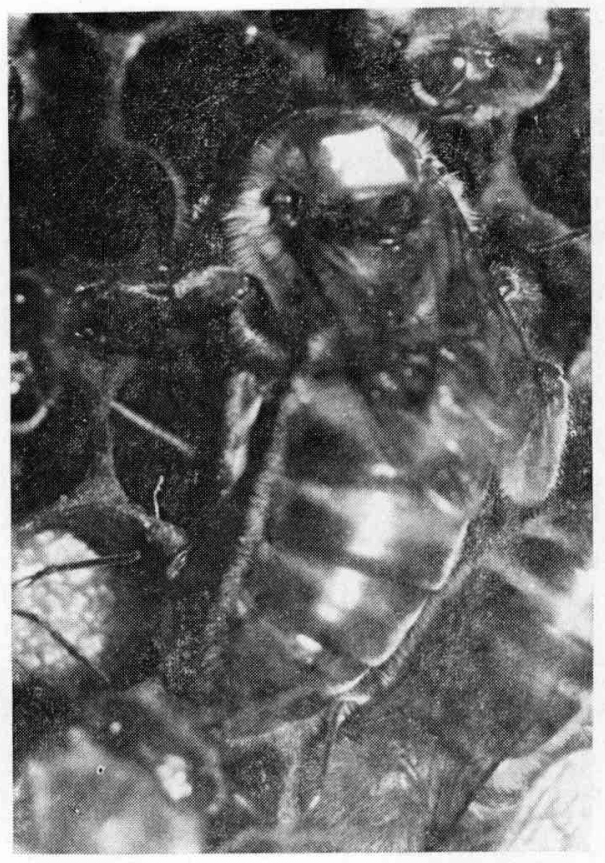

ABB. 5. - Beginn der Eiablage

Das Abdomen wird nach vorn gekrümmt und in die inspizierte Zelle eingeführt.

Fig. 5. - Début de la ponte

L'abdomen est recourbé vers l'avant et introduit dans la cellule inspectée.



Aв8. 6. - Eiablage

Nach dem Einführen des Abdomens dreht sich die Königin um die Längsachse der Zelle, sodaß der Kopf bei der Eiablage oft nach unten weist.

\section{Fic. 6. - Ponte}

Après avoir introduit l'abdomen, la reine se retourne autour de l'axe longitudinal de la cellule si bien que, pendant la ponte, il est fréquent que la tête regarde en bas.

Unterschiede zwischen Apis mellifica ligustica und Apis mellifica carnica wurden nicht festgestellt. Auch beim Eierlegen in Drohnenzellen konnte gegenüber Arbeiterinnenzellen keine Änderung des Verhaltens bemerkt werden. 


\section{IV. - EIABLAGE}

\section{UNTER VERÄNDERTEN BEDINGUNGEN : " DER BERLEPSCHVERSUCH "}

Im Frühjahr wurde ein starkes Volk auf reinen Drohnenbau gesetzt, lediglich die Randwaben, die normalerweise zu dieser Jahreszeit nie mit Eiern belegt werden, bestanden aus Arbeiterinnenzellen. Bei der Kontrolle nach drei Tagen wurden jedoch auf einer Randwabe Eier gefunden, und die Bienen hatten in den freien Raum zwischen der Randwabe und der Wand der Beute eine neue, ausschließlich aus Arbeiterinnenzellen bestehende Wabe gebaut. Die bestiftete Randwabe und die neugebaute Wabe wurden entfernt, sodaß jetzt nur noch Drohnenwaben vorhanden waren. Wieder aber wurde von den Bienen eine neue Arbeiterinnenwabe gebaut und sofort von der Königin mit Eiern belegt. Daraufhin wurde der Hohlraum zwischen der Waben und der Beutenwand mit Holztafeln gefüllt, sodaß kein Raum für neue Waben vorhanden war. Nun wurden sofort zwei Drohnenwaben bestiftet, und die verdeckelten Zellen wurden nach 18 Tagen kontrolliert. Dabei wurden hauptsächlich Drohnenpuppen gefunden. Lediglich in wenigen Zellen, die deutlich kleiner waren als normale Drohnenzellen (Durchmesser $5,9 \mathrm{~mm}$ ) wurden Arbeiterinnenpuppen gefunden. Dieser Versuch wurde mit einem zweiten Volk wiederholt, wobei streng darauf geachtet wurde, daß ausschließlich Drohnenzellen vorhanden waren. Bei der Kontrolle der verdeckelten Brutzellen wurden nur Drohnenpuppen gefunden. Im Herbst wurde dann der "Berlepschversuch " mit einem schwachen Volk durchgeführt, und jetzt erzeugte die Königin neben wenigen Drohnenpuppen hauptsächlich Arbeiterinnen, obwohl wiederum nur Drohnenzellen zur Verfügung standen.

Diese Ergebnisse stimmen mit den von v. Berlepsch und Freudenstein durchgeführten Experimenten recht gut überein. Im Frühjahr wurden die Drohnenzellen von Königinnen in starken Völkern mit unbefruchteten Eiern belegt; dagegen im Herbst wurden in einem schwachen Volk befruchtete Eier in Drohnenzellen abgelegt. Die Königin beantwortet also das Reizmuster der Drohnenzelle, wenn sie sich in einem starken Volk zu einer Jahreszeit, in der normalerweise Drohnen erzeugt werden, befindet, mit der Ablage unbefruchteter Eier. Im Spätsommer jedoch ist das Verhalten der Königin plastischer, und sie reagiert dann auf diese Zwangssituation biologisch sinnvoll.

\section{V. - BEHINDERUNG DER INSPEKTION}

Die Entscheidung über das Belegen einer Zelle wird anscheinend während der Inspektion getroffen. DaB dabei auch die Art der Zelle (Drohnen- oder Arbeiterinnenzelle) festgestellt wird, nach der sich ja die Befruchtung des Eies richtet, erscheint möglich. Daher soll zunächst eine Blockierung der Inspektion versucht werden.

Einer Königin wurde eine 8-9 mm lange Nylonborste auf die Stirnseite des Kopfes geklebt, um das Einführen des Kopfes in die Zelle während der Inspektion zu verhindern. Anschließend wurde die Königin in den Beobachtungskasten zurückgesetzt : nachdem die Königin zuerst beleckt und gefüttert wurde, begannen einige Arbeiterinnen die Borste mit den Mandibeln zu bearbeiten und intensiv 
daran zu zerren. Allmählich kamen immer mehr Bienen hinzu, und die Königin wurde an der Borste langsam zum Flugloch hingezogen. In diesem Stadium wurde Angriffsverhalten einiger Arbeiterinnen gegen die Königin beobachtet : die Arbeiterinnen krümmten das Abdomen, und es konnten deutliche Stechbewegungen gesehen werden.

Fünfzehn Minuten nach dem Zusetzen der Königin löste sich durch das kräftige Ziehen der Klebstoff vom Kopf der Königin, und die Nylonborste wurde zum Flugloch hinausgetragen.

Sofort wurde das Verhalten der Arbeiterinnen zur Königin normal, und die Königin begann mit der Eiablage.

Die Form des Kopfes der Königin scheint also für die Bienen wichtig zu sein. Deshalb muß die Verhinderung der Inspektion erreicht werden, ohne am Kopf Veränderungen vorzunehmen. Das soll durch Bekleben der Vorderbeine versucht werden.

Dazu wurde in zahlreichen Vorversuchen folgende Technik entwickelt : etwa $1 \mathrm{~mm}$ breite und $10 \mathrm{~mm}$ lange Streifen Klebefolie (Tesafilm) wurden mit Xylol gereinigt, dünn mit wasserunlöslichem Kontaktkleber bestrichen und fünfzehn Minuten getrocknet. Ein so vorbereiteter Streifen wurde mit der Mitte von vorn um die Tibia des Vorderbeines der Königin gelegt und beide Enden hinter der Tibia zusammengepreßt. Die so aufeinander geklebten Enden wurden derart abgeschnitten, daß sie $2 \mathrm{~mm}$ nach hinten wie eine kleine Fahne abstanden (im Folgenden wird diese Art der Behinderung als Fähnchen bezeichnet). (Abb. 7)

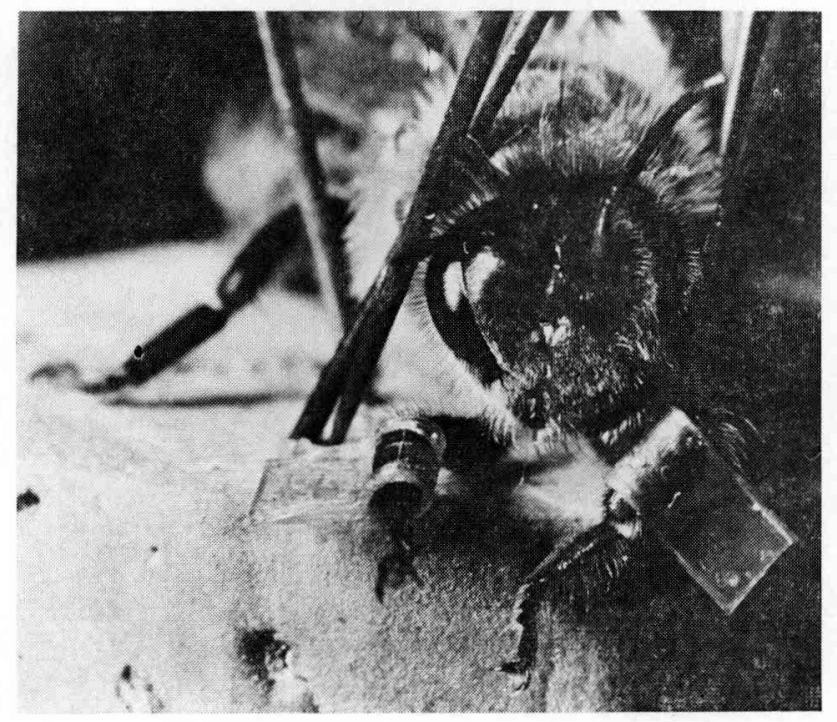

Aвв. 7. - Um die Tibien der Vorderbeine wurden Streifen aus Klebefolie gelegt : "Fähnchen»

FIG. 7. - Les tibias des pattes antérieures sont entourés de bandes de papier collant

Nach dem Bekleben beider Tibien in der beschriebenen Weise wurde die Königin zurück in den Beobachtungskasten gesetzt; die Arbeiterinnen leckten und fütterten die Königin, und nur einzelne Bienen begannen, an den Fähnchen zu 
zerren, was die Königin mit den Mittełbeinen abwehrte. Nach zehn Minuten wurde die erste Eiablage beobachtet. Bei der Inspektion legte die Königin die Tibien der Vorderbeine seitlich an den Kopf an und versuchte, sich in die Zelle hinein zu beugen. Doch die Fähnchen, die durch die Drehung der Tibien beim Anlegen an den Kopf, nun zur Seite abstanden, wurden senkrecht auf den Rand der Zelle gedrückt und verhinderten auf diese Weise das Einführen des Kopfes. Dabei befand sich der Kopf mit der Stirnseite parallel zur Wabenoberfläche, während die Antennen den Rand der Zelle betasteten. Das mittlere Beinpaar wurde dann wie bei einer normalen Inspektion von außen an die Zelle angelegt, und die Königin verharrte in dieser Stellung einen Augenblick, bevor sie das Abdomen in der oben beschriebenen Weise zur Eiablage einführte. So wurden während der ersten Stunde dreizehn Eiablagen beobachtet. In den Pausen wurde die Königin gepflegt und gefüttert. Sie führte bisweilen intensive Putzbewegungen aus, bei denen sie versuchte, die Fähnchen mit Hilfe der Mittelbeine abzustreifen. Nach 24. Stunden wurden die Fähnchen dagegen kaum mehr beachtet und nur hin und wieder von den Bienen beleckt.

Um die Auswirkung der Behinderung durch Fähnchen zu untersuchen, wurden drei Königinnen zunächst jeweils eine Wabe mit Drohnenzellen geboten, die sie ohne Fehler bestifteten, d.h. in den Drohnenzellen wurden bei der Kontrolle ausschließlich Drohnenpuppen gefunden. Nachdem diesen Königinnen Fähnchen angelegt waren, wurden wiederum Drohnenzellen geboten. In diesen Drohnenzellen fanden sich bei der Auswertung überwiegend Aurbeiterinnenpuppen. Daraufhin wurden die Fähnchen entfernt und den nun wieder unbehinderten Königinnen neuerlich Drohnenwaben geboten. Diese Drohnenzellen enthielten nur Drohnenpuppen; lediglich bei einer Königin (Is 5), die zur Zeit der Eiablage nur noch ein Vorderbein hatte, wurde eine einzige Arbeiterinnenpuppe neben 406 Drohnenpuppen gefunden (siehe Tabelle Nr. 1 A und Abb. 8).

\section{TABELLE 1 \\ Tableau 1}

\section{A. Behinderung der Königin durch Fähnchen}

Inhibition de la reine au moyen de bandes collantes

a. Vor dem Eingriff

Avant l'intervention

\begin{tabular}{|c|c|c|c|c|c|}
\hline & $\begin{array}{l}\text { Versuchs- } \\
\text { königin } \\
\text { Reine expér. }\end{array}$ & $\begin{array}{l}\text { Jahrgang } \\
\text { Vers. königin } \\
\text { Année de la } \\
\text { reine expér. }\end{array}$ & $\begin{array}{c}\text { Datum d. } \\
\text { Eiablage } \\
\text { Date de ponte }\end{array}$ & $\begin{array}{c}\text { Ausgewert. } \\
\text { Zellen } \\
\text { Cellules } \\
\text { recensèes }\end{array}$ & $\begin{array}{c}\% \text { Arbeiter.- } \\
\text { brut } \\
\% \text { couvain } \\
\text { ouvrière }\end{array}$ \\
\hline 1 & Is 4 & 1965 & $27-2-1967$ & 1909 & 0 \\
\hline 2 & Is 1 & 1964 & $16-3-1967$ & 1938 & 0 \\
\hline 3 & Is 5 & 1966 & $3-3-1967$ & 319 & 0 \\
\hline
\end{tabular}


b. Königin mit Fähnchen

Reine munie de papier collant

\begin{tabular}{l|c|c|c|c|c}
\hline & $\begin{array}{c}\text { Versuchs- } \\
\text { königin } \\
\text { Reine expér. }\end{array}$ & $\begin{array}{c}\text { Jahrgang } \\
\text { Vers. königin } \\
\text { Année de fa } \\
\text { reine expér. }\end{array}$ & $\begin{array}{c}\text { Datum d. } \\
\text { Eingriffs } \\
\text { Date intervent. }\end{array}$ & $\begin{array}{c}\text { Ausgewert. } \\
\text { Zellen } \\
\text { Cellules } \\
\text { recensées }\end{array}$ & $\begin{array}{c}\text { \% } \\
\text { Arbeiter.- } \\
\text { brut } \\
\text { \% couvain } \\
\text { ouvrière }\end{array}$ \\
\hline 1 & Is 4 & 1965 & $1-3-1967$ & 3377 & 86 \\
2 & Is 1 & 1964 & $19-3-1967$ & 1802 & 98 \\
3 & Is 5 & 1966 & $2-4-1967$ & 1332 & 93 \\
\hline
\end{tabular}

c. Nach Entfernung der Fähnchen

Après élimination des papiers collants

\begin{tabular}{|c|c|c|c|c|c|}
\hline & $\begin{array}{l}\text { Versuchs- } \\
\text { königin } \\
\text { Reine expér. }\end{array}$ & $\begin{array}{l}\text { Jahrgang } \\
\text { Vers. königin } \\
\text { Année de la } \\
\text { reine exper. }\end{array}$ & $\begin{array}{l}\text { Datum d. } \\
\text { Eiablage } \\
\text { Date de ponte }\end{array}$ & $\begin{array}{c}\text { Ausgewert. } \\
\text { Zellen } \\
\text { Cellules } \\
\text { recensées }\end{array}$ & $\begin{array}{c}\begin{array}{c}\% \text { Arbeiter.- } \\
\text { brut }\end{array} \\
\% \text { couvain } \\
\text { ouvrière }\end{array}$ \\
\hline 1 & Is 4 & 1965 & $20-4-1967$ & 1019 & 0 \\
\hline 2 & Is 1 & 1964 & $7-4-1967$ & 398 & 0 \\
\hline 3 & Is $5^{*}$ & 1966 & $28-4-1967$ & 407 & 0,25 \\
\hline
\end{tabular}

* Diese Königin hatte zum Zeitpunkt der Eiablage nur noch ein Vorderbein (vgl. Versuch 30). Cette reine n'avait qu'une patte antérieure au moment de la ponte (comp. expér. 30).

\section{B. Königinnen mit durchschnittenen Trochantern}

Reines dont les trochanters ont été sectionnés

\begin{tabular}{|c|c|c|c|c|c|c|}
\hline & $\begin{array}{l}\text { Versuchs- } \\
\text { königin } \\
\text { Reine expér. }\end{array}$ & $\begin{array}{c}\text { Jahrgang } \\
\text { Vers. königin } \\
\text { Annè de la } \\
\text { reine expér. }\end{array}$ & $\begin{array}{c}\text { Datum d. } \\
\text { Eiablage } \\
\text { Date de ponte }\end{array}$ & $\begin{array}{l}\text { Ausgewert. } \\
\text { Zellen } \\
\text { Cellules } \\
\text { recensées }\end{array}$ & $\begin{array}{c}\% \text { Arbeiter.- } \\
\text { brut } \\
\begin{array}{c}\% \text { couvain } \\
\text { ouvrière }\end{array}\end{array}$ & $\begin{array}{l}\text { Max. Rest. } \\
\text { Trochant. } \\
\text { Reste maxim. } \\
\text { Trochanter }\end{array}$ \\
\hline 4 & Is 3 & 1966 & $26-4-1967$ & 893 & 94 & $0,55 \mathrm{~mm}$ \\
\hline 5 & Is 1 & 1964 & $16-4-1967$ & 1824 & 65 & $0,33 \mathrm{~mm}$ \\
\hline 6 & $\mathrm{~V} 4$ & 1965 & $2-8-1967$ & 69 & 97 & $0,45 \mathrm{~mm}$ \\
\hline 7 & G $1 b$ & 1967 & $12-8-1967$ & 519 & 96 & $0,45 \mathrm{~mm}$ \\
\hline
\end{tabular}




\section{Königinnen mit durchschnittenen Femora}

Reines dont les fémurs ont été sectionnés

\begin{tabular}{|c|c|c|c|c|c|c|}
\hline & $\begin{array}{l}\text { Versnchs- } \\
\text { königin } \\
\text { Reine expér. }\end{array}$ & $\begin{array}{c}\text { Jahrgang } \\
\text { Vers. königin } \\
\text { Annce de la } \\
\text { reine expér. }\end{array}$ & $\begin{array}{c}\text { Datum d. } \\
\text { Eiablage } \\
\text { Date de ponte }\end{array}$ & $\begin{array}{c}\text { Ausgewert. } \\
\text { Zellen } \\
\text { Cellules } \\
\text { recensées }\end{array}$ & $\mid \begin{array}{c}\% \text { Arbeiter.- } \\
\text { brut } \\
\begin{array}{c}\% \text { couvain } \\
\text { ouvrière }\end{array}\end{array}$ & $\begin{array}{l}\text { Max. Rest. } \\
\text { femur. } \\
\text { Reste maxim } \\
\text { fémur. }\end{array}$ \\
\hline 8 & St $4 b$ & 1966 & $12-8-1967$ & 243 & 0 & $0,01 \mathrm{~mm}$ \\
\hline 9 & H 13 & 1966 & $12-6-1967$ & 268 & 38 & $1,0 \quad \mathrm{~mm}$ \\
\hline 10 & L 4 & 1966 & $19-6-1967$ & 8 & 100 & $0,55 \mathrm{~mm}$ \\
\hline 11 & St $4 a$ & $*$ & $13-7-1967$ & 198 & 0 & $0,83 \mathrm{~mm}$ \\
\hline 12 & H 33 & 1966 & $27-6-1967$ & 13 & 31 & $0,73 \mathrm{~mm}$ \\
\hline 13 & V 2 & 1966 & $3-7-1967$ & 3 & 33 & $0,8 \mathrm{~mm}$ \\
\hline 14 & $V_{1}$ & $*$ & $28-6-1967$ & 224 & 3 & $0,94 \mathrm{~mm}$ \\
\hline 15 & G 2 & 1965 & $6-7-1967$ & 38 & 44 & $0,85 \mathrm{~mm}$ \\
\hline 16 & V 3 & $*$ & $3-7-1967$ & 13 & 0 & $0,63 \mathrm{~mm}$ \\
\hline 17 & $\mathrm{Bc} 1$ & 1965 & $21-4-1968$ & 718 & 38 & $1,5 \mathrm{~mm}$ \\
\hline 18 & Bo $2 a$ & 1966 & $30-4-1968$ & 1360 & 12 & $0,85 \mathrm{~mm}$ \\
\hline 19 & Bo 4 & 1965 & $17-5-1968$ & 251 & 35 & $1,48 \mathrm{~mm}$ \\
\hline 20 & Bo $2 b$ & 1966 & $2-6-1968$ & 114 & 20 & $1,5 \mathrm{~mm}$ \\
\hline 21 & Bo 3 & 1966 & $2-6-1968$ & 623 & 17 & $1,3 \mathrm{~mm}$ \\
\hline
\end{tabular}

D. Königinnen mit durchschnittenen Tibien

Reines dont les tibias ont été sectionnés

\begin{tabular}{|c|c|c|c|c|c|c|}
\hline & $\begin{array}{l}\text { Versuchs- } \\
\text { königin } \\
\text { Reine expér. }\end{array}$ & $\begin{array}{c}\text { Jahrgang } \\
\text { Vers. königin } \\
\text { Année te la } \\
\text { reine expér. }\end{array}$ & $\begin{array}{l}\text { Datum d. } \\
\text { Eiablage } \\
\text { Date de ponte }\end{array}$ & $\begin{array}{c}\text { Ausgewert. } \\
\text { Zellen } \\
\text { Cellules } \\
\text { recensées }\end{array}$ & $\begin{array}{c}\% \text { Arbeiter.- } \\
\text { brut } \\
\begin{array}{c}\% \text { couvain } \\
\text { ouvière }\end{array}\end{array}$ & $\begin{array}{c}\text { Max. Rest. } \\
\text { tibia } \\
\text { Reste maxim. } \\
\text { Tibia }\end{array}$ \\
\hline 22 & L 5 & 1966 & $18-6-1967$ & 15 & 0 & * \\
\hline 23 & L 1 & 1965 & $19-6-1967$ & 30 & 0 & * \\
\hline 24 & L. 2 & 1965 & $19-6-1967$ & 91 & 0 & * \\
\hline 25 & Str $4 a$ & * & $13-6-1967$ & 101 & 0 & $0,8 \mathrm{~mm}$ \\
\hline 26 & H 33 & 1966 & $23-6-1967$ & 270 & 1 & $0,7 \mathrm{~mm}$ \\
\hline 27 & V $4 a$ & $*$ & $26-6-1967$ & 302 & 3 & $0,7 \mathrm{~mm}$ \\
\hline 28 & V 2 & 1966 & $29-6-1967$ & 363 & 4 & $0,98 \mathrm{~mm}$ \\
\hline 29 & G $1 a$ & 1966 & $6-7-1967$ & 17 & 0 & $0,67 \mathrm{~mm}$ \\
\hline
\end{tabular}


E. Königinnen, bei denen ein Vorderbein im Gelenk Coxa-Trochanter durchschnitten wurde Reines chez lesquelles une patte antérieure a été sectionnée dans l'articulation Coxa-Trochanter

\begin{tabular}{|c|c|c|c|c|c|}
\hline & $\begin{array}{l}\text { Versuchs- } \\
\text { königin }\end{array}$ & $\begin{array}{c}\text { Jahrgang } \\
\text { Vers. königin }\end{array}$ & $\begin{array}{c}\text { Datum d. } \\
\text { Eiablage }\end{array}$ & $\begin{array}{c}\text { Ausqewert. } \\
\text { Zellen }\end{array}$ & $\begin{array}{c}\% \text { Arbeiter.- } \\
\text { brut }\end{array}$ \\
\hline & Reine expér. & $\begin{array}{l}\text { Année de la } \\
\text { reine expér. }\end{array}$ & Date de ponte & $\begin{array}{l}\text { Cellules } \\
\text { recensèes }\end{array}$ & $\begin{array}{l}\% \text { couvain } \\
\text { ouvrière }\end{array}$ \\
\hline 30 & Is 5 & & $28-4-1967$ & 407 & 0,3 \\
\hline 31 & Is 3 & 1966 & 5- 4-1967 & 1000 & 0,7 \\
\hline
\end{tabular}

Versuch: 1

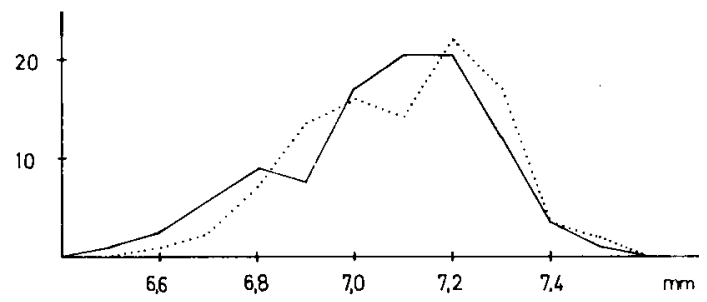

versuch: 2

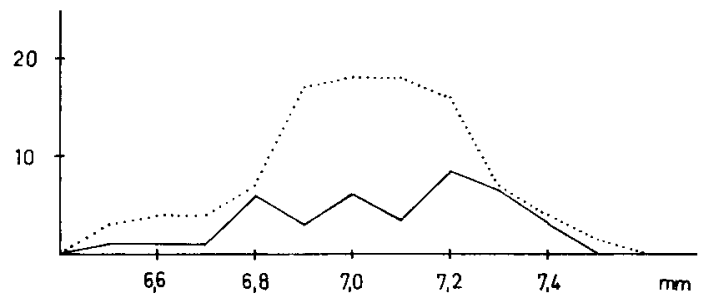

Versuch: 3

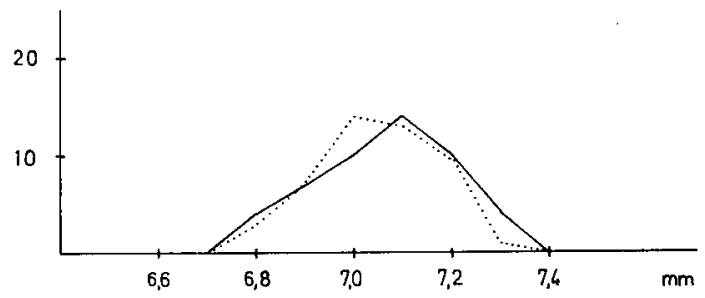

$8^{\circ}$

фభ

Aвв. 8. - Verteilung von Arbeiterinnen- und Drohnenbrut auf Drohnenzellen verschiedenen Durchmessers bei Königinnen mit Fähnchen Abszisse : Diagonaler Zelldurchmesser (mm).

Ordinate : Anzahl der Zellen.

FIG. 8. - Répartition du couvain de mâles et d'ouvrières dans les cellules mâles de diamètre variable lorsque les reines sont munies de papier collant

Abscisse : diamètre diagonal de la cellule (en mm).

Ordonnée : nombre de cellules. 


\section{VI. - AMPUTATION VON ANTENNEN UND VORDERBEINEN}

Da das Verhindern der Inspektion zu einer starken Beeinträchtigung des Unterscheidungsvermögens führt, liegt es nahe, daß die Königin eine Drohnenzelle beim Hineinbeugen in die Zelle während der Inspektion " erkennt ". Als Sitz der entsprechenden Rezeptoren kommen in erster Linie die Antennen und die Vorderbeine in Frage, die, wie oben beschrieben, in die Zelle eingeführt werden.

Die vollständige Ausschaltung beider Antennen führt zum baldigen Tod der Königin, da die Königin ohne Antennen keinen Kontakt mehr zu den Arbeiterinnen halten kann (FYG 1943). Die Amputation nur einer Antenne dagegen behindert die Königin bei der Eiablage und Zellunterscheidung nicht, wie in einem eigenen Versuch bestätigt werden konnte.

Nach Martin und Lindauer 1966 sind die Antennen zur maßgerechten Anlage der Wabenzellen entbehrlich. Unter der Annahme, daß die Königin zur Zellunterscheidung den gleichen Mechanismus benutzt wie die Arbeiterinnen beim Zellbau, sprechen auch diese Ergebnisse gegen eine Bedeutung der Antennen für das Erkennen der Drohnenzelle.

Deshalb erscheint es zunächst angebracht, den Einfluß der Vorderbeine zu untersuchen. Die Vorderbeine der Königin wurden dazu jeweils beidseitig etwa an der gleichen Stelle mit einer feinen Schere abgeschnitten und die abgeschnittenen Stücke ausgemessen. Von einer Betäubung der Königin wurde abgesehen, da dadurch das nötige sofortige Zusetzen ins Volk erschwert wird, bzw. mit großen Verlusten an Versuchsköniginnen verbunden ist.

Das Verhalten der Arbeiterinnen zu einer Königin ohne Vorderbeine ist weitgehend normal, wie aufgrund der Hofstaatbildung und dem Pflegen der Königin durch die Arbeiterinnen vermutet werden kann. Die Fortbewegung der Königin wird durch die Amputation der Vorderbeine nicht wesentlich eingeschränkt. Die Königin ist weiterhin in der Lage, von einer Wabe auf eine andere überzuwechseln. Allerdings konnten bei einigen Völkern etwa zwanzig Tage nach der Amputation Weiselzellen beobachtet werden. Simpson (1960) hält es für wahrscheinlich, daß die Amputation der Vorderbeine die Verteilung der Königinnensubstanz behindert und daher den Bau von Weiselzellen induziert. Bei der Inspektion und der Eiablage führt die Amputation der Vorderbeine anfänglich zu einer leichten Verlängerung des Handlungsablaufes, während sonst keine Unterschiede zum "Normalverhalten" bemerkt wurden. Auch die Lebensdauer der Königin scheint kaum beeinträchtigt zu sein; zum Beispiel wurde eine amputierte Königin ohne Schwierigkeiten überwintert.

Es wurden 26 Versuche durchgeführt, bei denen die Vorderbeine der Versuchsköniginnen beiderseits jeweils etwa an der gleichen Stelle abgeschnitten wurden. Die Königinnen wurden in der bereits beschriebenen Weise getestet (Abb. 9 und 10). Die Ergebnisse sind in Tab. 1 B-D zusammengefasst.

Für einzelne Versuche ist die Verteilung der Arbeiterinnen- und Drohnenbrut auf Drohnenzellen unterschiedlicher Grösse in den Abbildungen 11a-11c graphisch dargestellt.

Die Königinnen mit durchschnittenen Trochantern (Versuch 4-7) zeigen nahezu den gleichen Anteil an falschbesetzten Zellen wie die Fähnchenköniginnen. 


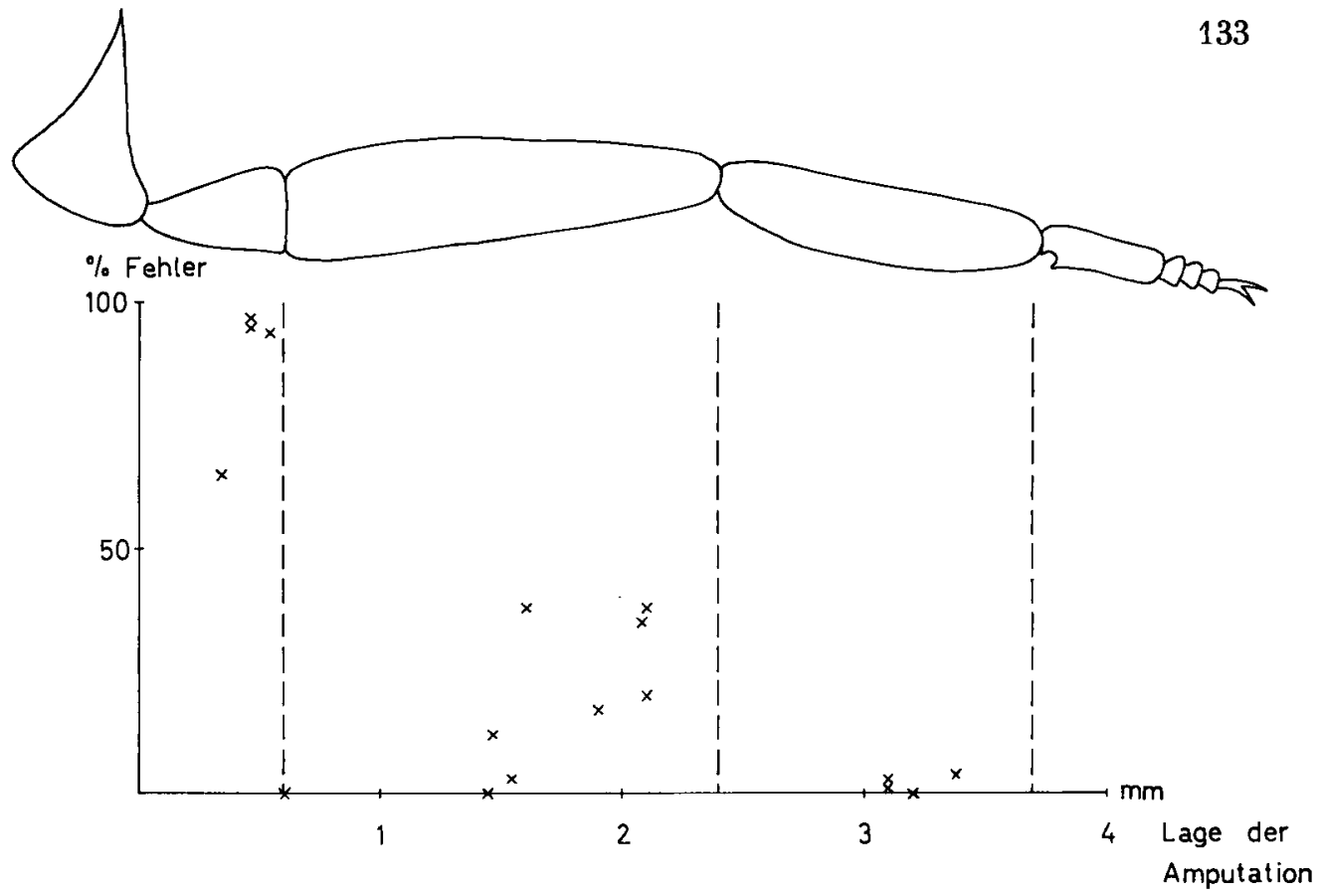

Aв8. 9. - Häufigkeit von Fehlern bei der Eiablage

nach Amputation beider Vorderbeine an verschiedenen Stellen

Abszisse : maximaler Rest der Vorderbeine.

Ordinate : Arbeiterinnenpuppen in Drohnenzellen (Fehler).

Fic. 9. - Fréquence d'erreurs de ponte

après amputation des deux pattes antérieures à différents endroits

Abscisse : reste maximal de la patte antérieure.

Ordonnée : pupes d'ouvrières dans les cellules de mâles (erreurs).

$\%$ Fehler

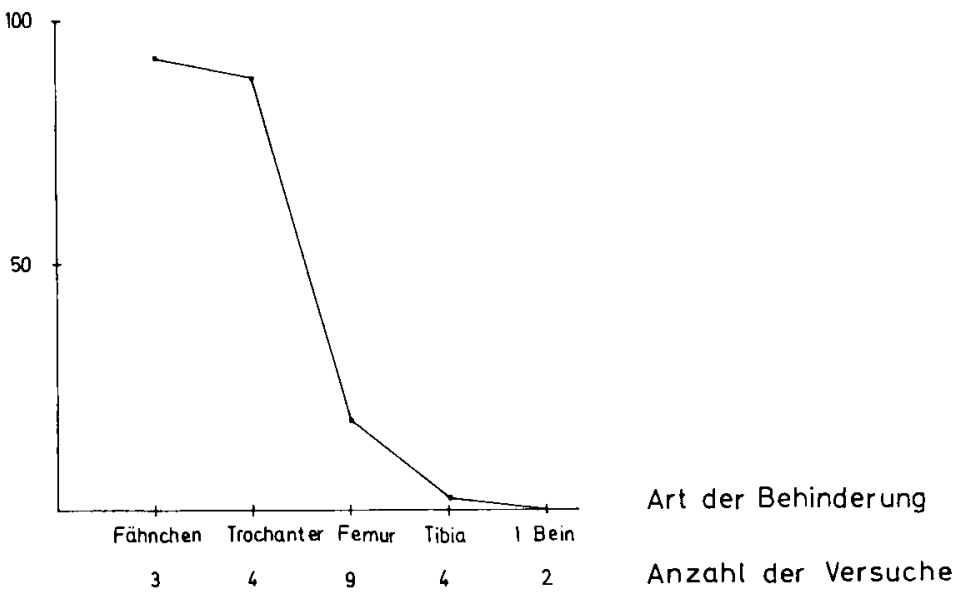

Aв8. 10. - Verteilung der Mittelwerte von 22 Versuchen (mindestens 50 ausgewertete Zellen)

Fig. 10. - Répartition des valeurs moyennes pour 22 expériences (au moins 50 cellules recensées)

Art der Behinderung : type de blocage expérimental.

Anzall der Versuche : nombre d'expériences. 
Nur Is 1 (Versuch 5) weist einen kleineren Fehleranteil von nur $65 \%$ gegen etwa $95 \%$ bei den drei anderen Königinnen auf. Dabei ist zu bemerken, daß diese Königin einen Monat vorher mit Fähnchen getestet worden war (Versuch 2).

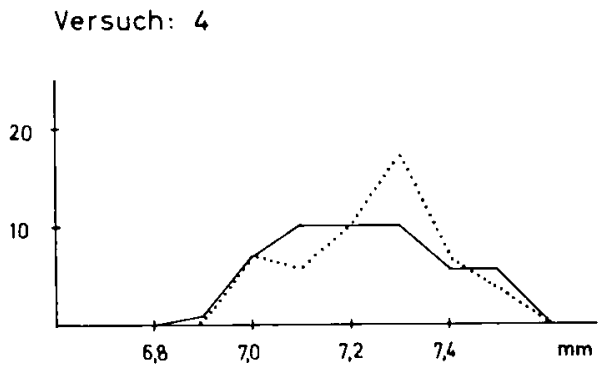

Versuch: 5

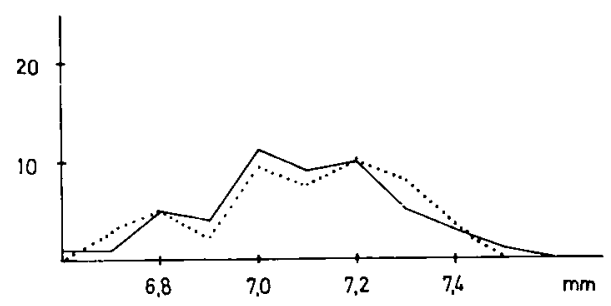

Versuch: 6

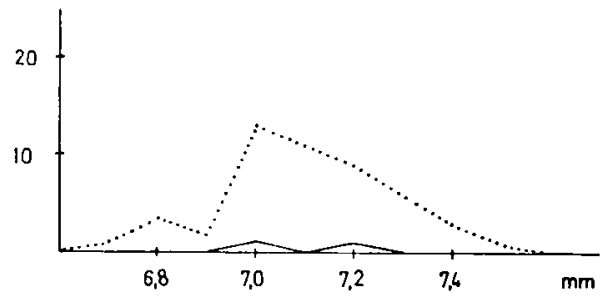

Versuch: 7

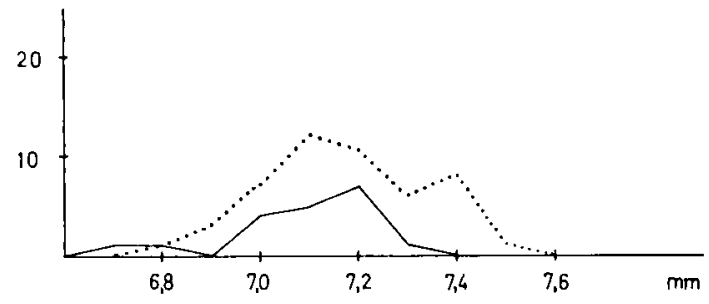

$-\sigma^{\circ} \sigma^{\circ}$

$\phi \varnothing$

ABB. $11 a$

FIG. $11 a$ 
Bei den Versuchen mit durchschnittenen Femora (Versuch 8-21) treten bei Versuch 8 und Versuch 11 keine Fehler auf, während bei Versuch 9, 17, 19 das Erkennen der Drohnenzellen stärker gestört ist. (Alle Versuche, bei denen nur weniger als 50 Zellen ausgewertet werden konnten, haben wegen der mangelnden statistischen Sicherung eine geringe Aussagekraft, sodaß es nicht sinnvoll erscheint, auf diese Versuche näher einzugehen).

Versuch: 8

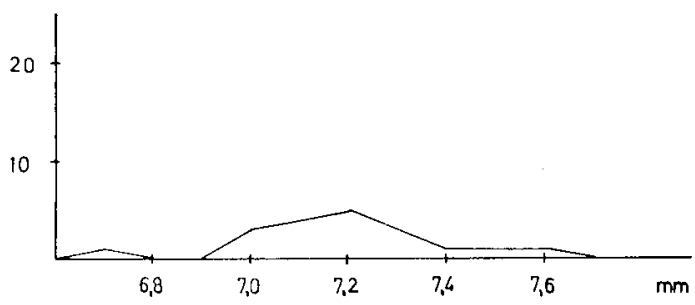

Versuch: 9



Versuch: 15

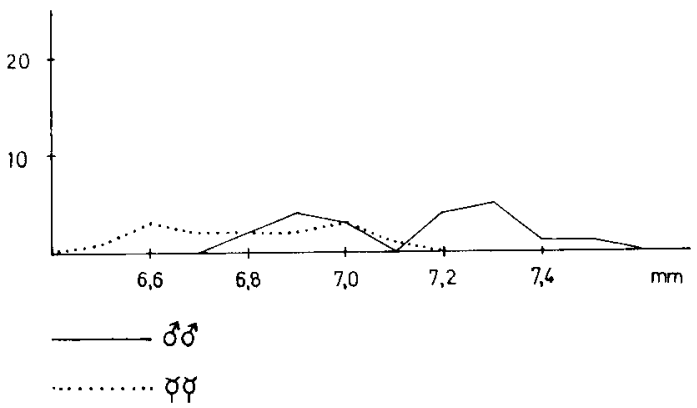

Aвв. $11 b$

Fig. $11 b$

Durchschnittene Tibien (Versuch 22-29, Abb. 11c) führen zu nur geringen Störungen. Die einheitlichen Ergebnisse dieser Versuchsgruppe sind im Vergleich zu den Auswirkungen der durchschnittenen Femora bemerkenswert. Auch nehmen die Königinnen mit durchschnittenen Tibien noch Größenunterschiede zwischen den einzelnen Zellen wahr, denn Arbeiterinnenpuppen wurden vorwiegend in kleineren Drohnenzellen gefunden. 
Versuch: 28

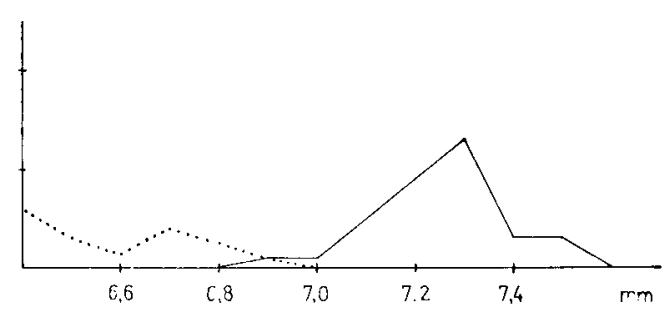

Versuch: 26

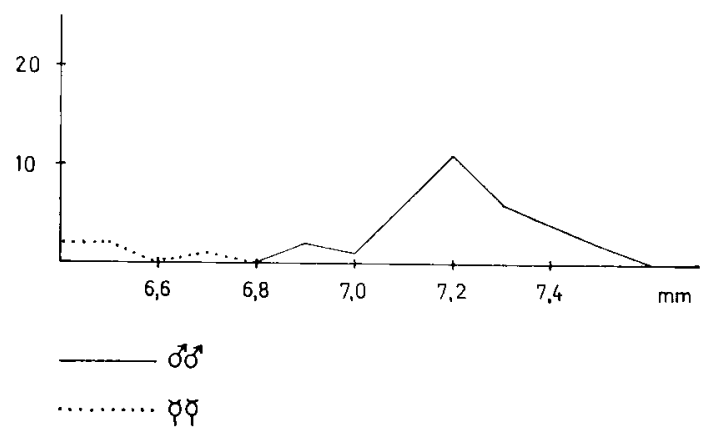

Авв. $11 c$

Fig. $11 c$

Авв. 11 a-c. - Verteilung von Arbeiterinnen- und Drohnenbrut auf Drohnenzellen verschiedenen Durchmessers bei amputierten Königinnen

11a. Amputation im Trochanter.

11b. Amputation im Femur.

11c. Amputation in der Tibia.

Abszisse : Diagonaler Zelldurchmesser (mm).

Ordinate : Anzahl der Zellen.

FIG. 11 a-c. - Rëpartition du couvain de mâles et d'ouvrières dans les cellules mâles de diamètre variable lorsque les reines sont amputées

11a. Amputation au niveau du trochanter.

11b. Amputation au niveau du fémur.

11c. Amputation au niveau du tibia.

Abscisse : diamètre diagonal de la cellule (en mm).

Ordonnée : nombre de cellules.

Die Amputation von nur einem Vorderbein beeinträchtigt, wie in Versuch 30 und 31 gezeigt wird, das Erkennen nur geringfügig (Tab. 1 E).

Da ein angeschnittenes Beinglied bis zum proximalen Gelenk austrocknet, scheint die Zusammenfassung der Amputationsversuche in Gruppen biologisch sinnvoll zu sein (Abb. 9). 


\section{DISKUSSION}

Eingehend wurde das Eilegeverhalten von sechs Königinnen beobachtet. Diese Königinnen sowie alle anderen, die beim Eierlegen beobachtet werden konnten, führten bei der Inspektion die Vorderbeine seitlich an den Kopf angelegt mit in die Zelle ein. Diese Verhaltensweise kann somit wohl nicht als individuelle Abweichung angesehen werden, obwohl dieses Verhalten nach Kenntnis des Autors bisher nicht beschrieben wurde.

Durch Ankleben von Fähnchen wurde das Hineinbeugen der Königin in die Zelle reversibel verhindert. Dieser Eingriff kann als eine leichte Störung in Bezug auf den Allgemeinzustand der Königin gelten, da die Legeleistung danach nicht zurückgeht. Die Fähnchen führen anfänglich zu einem gehäuften Auftreten von Mehrfachbestiftungen.

Der Einfluß der Fähnchen sowie der partiellen beidseitigen Amputation der Vorderbeine auf das Erkennen der Drohnenzelle wurde untersucht. Dabei wurden zur Geschlechtsbestimmung die verdeckelten Brutzellen herangezogen, da das Geschlecht der darin enthaltenen Puppen exakt und sehr einfach mit dem bloßen Auge festgestellt werden kann. Natürlich muß dabei berücksichtigt werden, daß ein Teil der gelegten Eier während der Entwicklung zu Grunde gehen kann. So fressen z. B. die Arbeiterinnen selektiv alle diploiden Drohnenmaden nach dem Schlüpfen aus den Eiern (Woyke 1963). Es besteht also die Gefahr, durch ein gerichtetes Ausfressen der Bienenmaden durch die Arbeiterinnen ein verzerrtes Ergebnis zu erhalten. Bei den meisten Versuchen konnte auf Grund der lückenlosen Brutfläche auf den Testwaben das Entfernen der Larven weitgehend ausgeschlossen werden; denn jede ausgefressene Zelle muß, da die Königin nach dem Eierlegen keinen Zutritt mehr zu der Testwabe hat, unbesetzt bleiben und als Lücke zwischen den bei der Auswertung verdeckelten Zellen bemerkt werden. Bei den Versuchen dagegen, bei denen auf der Testwabe weniger als ca 200 Brutzellen gefunden wurden, ist sicher ein Teil der Eier verloren gegangen, da diese Brutflächen bisweilen lückenhaft waren. Weil aber auch bei diesen Versuchen Arbeiterinnenpuppen in Drohnenzellen gefunden wurden, werden offenbar nicht selektiv alle falsch plazierten Maden entfernt. Weiterhin spricht die Übereinstimmung mit den Experimenten, bei denen aufgrund der geschlossenen Brutfläche ein Entfernen der Maden ausgeschlossen werden konnte, gegen ein gerichtetes Ausfressen der Brut durch die Arbeiterinnen. Außerdem muß beachtet werden, daß es sich bei allen diesen Versuchen um völlig normale Arbeiterinnen- und Drohnenmaden handelt und nicht um abnorme Maden, wie sie die diploiden Drohnenmaden sicherlich darstellen. Um jedoch direkt nachzuweisen, daß falsch plazierte Larven nicht bevorzugt von den Arbeiterinnen entfernt werden, wurden bei zwei Versuchen die mit Eiern belegten Testwaben in einen Brutschrank überführt. Dort wurden die Eier bei $34{ }^{\circ} \mathrm{C}$ und $100 \%$ Luftfeuchtigkeit zum Schlüpfen gebracht. Alle 60 Minuten wurden die Waben kontrolliert und die frischgeschlüpften Maden mit Hilfe eines speziell umgearbeiteten Umlarvlöffels unter einem Stereomikroskop aus den Zellen herausgenommen und vorsichtig jeweils fünf bis sieben Maden in einem kleinen Wachsbecher (künstliche Weiselzelle) auf Königinnenfuttersaft gelegt. Nachdem auf diese Weise etwa 80 Maden von jeder Wabe entnommen 
waren, wurden die Testwaben in die Versuchsvölker zurück gehängt, während die herausgenommenen Maden 48 bis 60 Stunden im Brutschrank weiterhin bei $34{ }^{\circ} \mathrm{C}$ und $100 \%$ Luftfeuchtigkeit belassen wurden. Das Geschlecht dieser Larven wurde dann nach der Methode von Nielsen und Bohart (1967) und nach Woyke (1963) bestimmt. Dabei wurden zur Geschlechtsunterscheidung Kutikulastrukturen auf dem 12. Sternit herangezogen, die ausschließlich bei Drohnenmaden vorhanden sind (ZANDER 1916). Außerdem habe ich, soweit wie möglich, die Unterschiede in der Anordnung der Imaginalscheiben zwischen Arbeiterinnen- und Drohnenmaden berücksichtigt.

Diese Ergebnisse wurden mit den Werten verglichen, die bei der Auswertung der in den Völkern aufgezogenen Maden erhalten wurden, deren Geschlecht aufgrund der Puppenunterschiede bestimmt wurde. (Tab. 2). In beiden Fällen stimmen alle Werte gut überein, so daß auf weitere Versuche verzichtet werden konnte.

Tabecle: 2. Geschlechtsbestimmung an Maden und Puppen

Tableau 2. Détermination ${ }^{-} d u$ sexe sur les larves et pupes

\begin{tabular}{c|c|c|c|c|c}
\hline $\begin{array}{c}\text { Versuchs } \\
\text { königin } \\
\text { Reine expér. }\end{array}$ & $\begin{array}{c}\text { Entnomm. } \\
\text { Eier } \\
\text { Eufs prélevés }\end{array}$ & $\begin{array}{c}\text { Ausgewert. } \\
\text { Puppen } \\
\text { Pupes } \\
\text { recensies }\end{array}$ & $\begin{array}{c}\text { Ausgewert. } \\
\text { Maden } \\
\text { Larves } \\
\text { recensées }\end{array}$ & $\begin{array}{c}\% \text { Arbeiter- } \\
\text { Maden } \\
\% \text { larves } \\
\text { ouvrières }\end{array}$ & $\begin{array}{c}\% \text { Arbeiter- } \\
\text { Puppen } \\
\% \text { pupes } \\
\text { ouvrières }\end{array}$ \\
\hline Bo 2 & 107 & 52 & 62 & 16 & 19 \\
\hline Bo 3 & 55 & 556 & 67 & 17 \\
\hline
\end{tabular}

Bei der Behinderung durch Fähnchen sowie nach Ausschaltung beider Trochanter der Vorderbeine ist die Zellunterscheidung der Königin stark beeinträchtigt. In beiden Fällen scheint die Perzeption der Zellgröße nicht mehr möglich zu sein, da sich im Gegensatz zu den Ergebnissen bei durchschnittenen Tibien keine Unterschiede in den Durchmessern der Drohnenzellen mit Arbeiterinnenund Drohnenbrut ergeben (Abb. 8, 11a). Die Königin scheint also die Drohnenzelle weitgehend mit Hilfe der Vorderbeine zu erkennen, wobei Tibia und Tarsus nur eine geringe Bedeutung zukommen. Auch die Amputation von nur einem Vorderbein verursacht lediglich unwesentliche Störungen.

Über die Art des Meßvorganges lassen sich aufgrund der vorgelegten Ergebnisse keine Aussagen machen. So ist nicht klar, ob der diagonale Zelldurchmesser oder eine andere Zellgrösse gemessen wird, die diesem proportional ist, wie z.B. der Abstand zweier Zellwände oder die Breite einer Zellwand. Ebenso bleibt unbekannt, welcher Rezeptor, der proximal vom Femur vermutet werden kann, bei dieser Messung benutzt wird.

Auch bei den Versuchen mit Fähnchen und durchschnittenen Trochantern wurden einige Drohnenpuppen auf den Testwaben gefunden. Es kann also vermutet werden, daß die Königin über einen weiteren Mechanismus zum Erkennen 
der Drohnenzellen verfügt, der aufgrund von Unterschieden zwischen Drohnenund Arbeiterinnenzellen arbeitet, die nicht proportional zum diagonalen Zelldurchmesser sind. Welche Reize zur Zellunterscheidung in diesen Fällen dienen, bleibt offen. $\mathrm{Ob}$ in diesem Zusammenhang die Freudenstein'sche Hypothese (siehe Seite 7 bis 8) eine Erklärung bietet, müßte durch weitere Untersuchungen geklärt werden.

Bei keinem Versuch wurde Drohnenbrut in Arbeiterinnenzellen gefunden, obwohl die Königinnen während der Versuche wesentlich mehr (etwa acht bis zehnmal soviel) Eier in Arbeiterinnenzellen legten als in Drohnenzellen. Der physiologische "Normalvorgang " ist also offenbar die Freisetzung von Sperma während des Eilegeaktes. Die Blockierung der Spermazugabe würde dann aufgrund des spezifischen Reizmusters der Drohnenzelle erfolgen, sofern die physiologischen Voraussetzungen (v. BERLEPSCH, 1860) gegeben sind. Damit wäre auch geklärt, warum die Weiselzelle, die in ihrem Bau von einer Drohnenzelle wesentlich abweicht, von der Königin mit einem befruchteten Ei belegt wird.

Reçu pour publication en décembre 1969. Eingegangen im Dezember 1969.

\section{RESUME}

On a émis plusieurs hypothèses sur le rapport existant entre le déterminisme de fécondation de l'œuf et le type de cellule dans laquelle cet œuf a été pondu. Dans le présent travail, on essaiera de contribuer à l'explication de ce phénomène par la voie expérimentale.

\section{MATÉRIEL ET MÉTHODE}

Dans ces expériences on a utilisé de fortes colonies d'abeilles comprenant au moins cinq cadres de couvain. On a travaillé principalement avec Apis mellifica carnica et Apis mellifica ligustica.

Dès qu'une reine avait pondu dans les premières cellules de mâles on retirait les cadres et on procédait à l'intervention sur la reine. On ôtait également les œufs de mâles qu'elle continuait à pondre après l'intervention. Pendant quinze à dix-huit jours après la ponte du premier oeuf, on inspectait les cadres de mâles pour déterminer le sexe des larves devenues nymphes entre temps. Les cellules étaient mesurées à l'aide d'un calibre et toutes celles qui avaient au moins $6,5 \mathrm{~mm}$ de diamètre étaient considérées comme cellules de mâles. Dans les expériences on n’a utilisé que des reines qui, avant l'intervention, avaient pondu exclusivement des cufs non fécondés dans les cellules de mâles. 


\section{RÉSULTATS}

Par des observations prolongées du comportement de ponte on s'est aperçu que la reine, lors de l'inspection, introduit ses deux pattes antérieures et sa tête dans la cellule. Dans les conditions qui ne sont pas tout à fait naturelles de la ruche d'observation, elle pond environ un ouf pour deux inspections. On n'a pu remarquer aucune différence entre le comportement dans les cellules de mâles et dans les cellules d'ouvrières. Il semble donc que la décision de pondre ou non un œuf dans une cellule soit prise pendant l'inspection; il est vraisemblable que c'est également à ce moment que le type de cellule est pris en considération. On a donc élaboré une méthode de blocage d'inspection: les tibias de la première paire de pattes ont été entourés d'une bande de papier collant de $1 \mathrm{~cm}$ de large formant deux petits rectangles vers l'arrière (fig. 7).

Le comportement d'une reine ainsi équipée de papier collant semble tout à fait normal et en particulier elle est nourrie et soignée par les ouvrières. Mème la capacité de ponte qui, lors des perturbations de la colonie, est souvent fortement réduite, demeure constante. Pour vérifier les effets de cette méthode sur la différenciation des cellules, on a présenté successivement à trois reines un rayon de cellules de mâles qu'elles ont garni d'œufs sans faire d'erreur : c'est-à-dire qu'on a trouvé uniquement des nymphes mâles dans les cellules de mâles. Après avoir collé les pattes de ces reines on leur a présenté de nouveau les cellules de mâles. Dans ces cellules de mâles on a trouvé surtout des nymphes d'ouvrières. Lorsqu'on retirait ensuite le papier collant, les reines libérées ne pondaient dans les cellules de mâles que des oufs non fécondés.

A la suite de cela, on a étudié le rổe des pattes antérieures sur la reconnaissance des cellules de mâles : les pattes antérieures des reines ont été sectionnées des deux côtés au même endroit et les reines testées de la façon précédemment décrite (tabl. 1). Étant donné que si l'on coupe un article de patte, il sèche jusqu'à l'articulation suivante, il semble que les résultats des expériences d'amputa. tion en groupes soient significatifs (fig. 10).

Dans le cas du papier collant ou de l'amputation des pattes antérieures jusqu'au trochanter, il semble que la perception de la taille des cellules ne soit plus possible puisque, contrairement aux expériences d'amputation des tibias, il n'y a aucune différence entre les diamètres des cellules de mâles, qu'elles contiennent du couvain d'ouvrière ou des pupes de mâles (fig. 11). La reine reconnaît donc les cellules de mâle d'après leur taille, pendant l'inspection, à l'aide de ses pattes antérieures, le tibia et le tarse ne jouant qu'un rôle mineur.

\section{LITERATUR}

1. Adam A., 1912. Bau und Mechanismus des Receptaculum seminis bei Bienen, Wespen und Ameisen. Zool. $J b ., 35,1-74$.

2. v. BerLepsch A., 1873. Die Biene und ihre Zucht mit beweglichen Waben in Gegenden ohne Spätsommertracht. J. Schneider, Mannheim.

3. Bresslau E., 1905. Der Samenblasengang der Bienenkönigin. Zool. Anz., 29 (10), 299-325.

4. Butler C. O., 1960. Bee Department. XX Rep. Rothamsted exp. Sta., 168-313.

5. v. Buttel-Reepen H., 1915. Leben und Wesen der Bienen. Viehweg u. Sohn, Braunschweig.

6. Dzierzon J., 1849. Neue verbesserte Bienenzucht des Pfarrers Dzierzon. Selbstverlag d. herausgeb. Bruckisch, 3. Aufl. 
7. Flanders S. E., 1950. Control of Sex in the Honeybee. Sci. Monthly 71, 235-240.

8. Freudenstein K., 1938. Das Wesen der Bienen. Pabst, Königsbrück.

9. Freudenstein K., 1938. Zur Geschlechtsbestimmung bei der Honigbiene. Vhdl. 7. Intern. Kongress Entomol., 3, 1772-1777.

10. v. Frisch K., 1921. Über den Sitz des Geruchsinnes bei Insekten. Zool. Jb. Abt. Physiol., $38,1-68$.

11. v. Frisch K., 1964. Aus dem Leben der Bienen. Springer, Berlin Heidelberg New York.

12. v. Frisch K., 1965. Tanzsprache und Orientierung der Bienen. Springer, Berlin Heidelberg New York.

13. Fyg W., 1938. Benussi-Bossi's Hypothese über die Geschlechtsbestimmung im Bienenstaat. Schweiz. Bienenztg. 10, 637-647.

14. Fyg W., 1940. Eine sonderbare Legestörung bei einer Bienenkönigin. Schweiz. Bienenztg. $6 d, 1-7$.

15. FyG. W., 1943. Experimentelle Untersuchungen über den Eilegeakt der Bienenkönigin. Mitt. Schweiz. Entomol. Ges. 28, 493-521.

16. Gontarski H., 1935. Wabenzellmaße bei Apis mellifica. Z. vergl. Physiol. 21, 681-698.

17. Goetze G., 1940. Die beste Biene. Liedloff, Loth u. Michaelis, Leipzig.

18. Huber F., 1814. Nouvelles observations sur les abeilles. Tome 1 et 2 , Paris Genève.

19. LaIdLaw H. H., 1944. Artificial insemination of queen bees : Morphological basis and results J. Morph. 74, 429-465.

20. LAU D., 1959. Beobachtungen und Experimente über die Entstehung der Bienenwabe. Zool. Beitr. 4, 233-306.

21. MarkL H., 1962. Borstenfelder an den Gelenken als Schweresinnesorgane bei Ameisen und anderen Hymenopteren. $Z$. vergl. Physiol. 45, 475-569.

22. Martin H., 1964. Leistungen des topochemischen Sinnes bei der Honigbiene. Z. vergl. Physiol. $50,254-292$.

23. Martin H., Lindader M., 1966. Sinnesphysiologische Leistungen beim Wabenbau der Honig. biene. Z. vergl. Physiol. 53, 372-404.

24. Nachtsheim H., 1914. Zytologische Studien über die Geschlechtsbestimmung bei der Honigbiene (Apis mellifica). Arch. Zellforsch. 11, 169-241.

25. Nielsen R. A., Bohart G. E., 1967. Sex Characters of Larval Bees. Ann. Entomol. Soc. Amer. $60(2), 414-419$.

26. Petrunkewitsch A., 1901. Die Richtungskörper und ihr Schicksal im befruchteten und unbefruchteten Bienenei. Zool. Jb. Abt. Anat. 14, 573-608.

27. Ribbands C. R., 1953. The Behaviour and Social Life of Honeybees. Bee Research Association, London.

28. Ruttner F., 1961. Innervation der Fortpflanzungsorgane der Honigbiene. Z. Bienenforschg. 5 (8), 253-266.

29. Simpson J., 1960. Induction of Queen Rearing in Honey Bees Colonies by Amputation of their Queens Frontlegs. Bee World 41, 286-287.

30. v. Siebold C. Th., 1856. Wahre Parthenogenesis bei Schmetterlingen und Bienen. Engelmann, Leipzig.

31. Snodgrass R. E., 1925. Anatomy and Physiology of the Honeybee. Mc Graw-Hill Book Comp., New York, London.

32. Tinbergen N., 1964. Instinktlehre Paul Parey 3. Aufl., Berlin. 
33. WoYke J., 1963. Rearing and Viability of Diploid Drone Larvae. J. Apicult. Res. 2, 77-84.

34. Zander E., Löschel F., Meier K., 1916. Die Ausbildung des Geschlechts bei der Honigbiene (Apis mellifica). Z. angew. Entomol., 3, 1-74.

35. Zander E., 1922. Der Bau der Biene. Eugen Ulmer, Stuttgart.

36. ZaNDER E., Werss K., 1964. Das Leben der Biene. Eugen Ulmer, Stuttgart. 